\title{
Efficient demulsification of ultralow-concentration crude oil-in-water emulsion by three-dimensional superhydrophilic channels
}

\author{
Jian Jin ${ }^{1}$, Jun Su${ }^{1}$, Chengjie Xiang ${ }^{1}$, Bo Xu' ${ }^{2}$ Kaiqi Zhao ${ }^{1}$, Hongyun $\mathrm{Li}^{1}$ and Lidong Sun ${ }^{1 *}$
}

\begin{abstract}
Efficient extraction of crude oil, the major energy resource of current concern and high demand worldwide, is of paramount importance in both energy and environmental fields. However, it remains a great challenge to separate the crude oil-in-water emulsions with an ultralow oil content of $<200 \mathrm{ppm}$. Here, the three-dimensional and superwetting channels are developed by coating titanium foams with anodic $\mathrm{TiO}_{2}$ nanotube arrays. The channels render superhydrophilic and underwater superoleophobic feature, which enables rapid formation of water channels that expel the oil droplets. A high separation efficiency of $\sim 96.8 \%$ and low total organic carbon content of $\sim 6 \mathrm{ppm}$ are thus achieved for the ultralow-concentration crude oil-in-water emulsions. The pressure and time dependence of the separation process is systematically studied with a critical pressure of $12.25 \mathrm{kPa}$. Such a high performance is close to the theoretical limit imposed by the ultralow concentration, and shows obvious advances over either organic membranes or inorganic frameworks.
\end{abstract}

Keywords: oil/water separation, oil-in-water emulsion, crude oil, superhydrophilic channels, $\mathrm{TiO}_{2}$ nanotubes

\section{INTRODUCTION}

Crude oil is one of the most important strategic resources, and has been the worldwide focus as a nonrenewable and scare energy resource. The oil exploitation usually utilizes a large amount of water to drive out the oils from the strata. As such, oil/water separation is a crucial process to extract the oil and meanwhile clean the water [1-5]. In general, the free crude oil (droplets $>150 \mu \mathrm{m}$ ) can be easily removed by biodegradation $[6,7]$, adsorption [8-10], and skimming $[11,12]$. However, it is difficult to directly separate the stable crude oil-in-water emulsions (droplets $<20 \mu \mathrm{m}$ ) especially in the case of low concentrations.

The crude oil generally exists in the form of mixture that mainly consists of various alkanes [13]. A single species of alkanes has been widely employed as an analogue to study the separation process. Zhu et al. [14] separated the isooctane-inwater emulsion using zwitterionic nanosized hydrogel-grafted poly(vinylidene fluoride) (PVDF) microfiltration membrane, with a separation efficiency of $99.8 \%$ and total organic carbon content (TOC) of $19 \mathrm{ppm}$ in the collected filtrate. Zhang et al.
[15] studied the separation of hexadecane-in-water emulsions, and obtained a low TOC content of $<40 \mathrm{ppm}$ in the filtrate by poly(acrylic acid)-grafted PVDF filtration membrane. However, rare studies have been reported to demulsify the crude oil-inwater emulsion with high separation efficiency and low oil content in the filtrate. Nikolov et al. [16] reported the separation of 500-800 ppm crude oil-in-water emulsion with a separation efficiency of about $95 \%$ using air flotation. Shi et al. [17] separated the crude oil-in-water emulsion with a volume ratio of 1:50 by waste brick powders-coated PVDF membrane, and the residual oil content of the filtrate was $115 \mathrm{ppm}$ with a separation efficiency above $99.3 \%$. Xu et al. [18] demulsified the crude oilin-water emulsion containing $2.0 \mathrm{~g}$ oil and $198.0 \mathrm{~g}$ water with an efficiency of $95.5 \%$ using magnetically responsive multiwalled carbon nanotubes. Zhang et al. [19] separated the crude oil-inwater emulsion containing $1000 \mathrm{ppm}$ crude oil using a zwitterionic nanohydrogel-grafed PVDF nanofibrous membrane with a crude oil removal efficiency of $98.7 \%$ and TOC content of below $13 \mathrm{ppm}$. All of these studies present relatively low separation efficiencies or high oil contents in the filtrate, even for emulsions of high concentration. It thus remains a great challenge to separate the crude oil-in-water emulsions of ultralow concentration $(<200 \mathrm{ppm})$, toward efficient oil extraction and water purification.

In this work, three-dimensional (3D) superwetting channels are employed to separate the ultralow-concentration emulsions of crude oil, in the presence of conformal coatings of $\mathrm{TiO}_{2}$ nanotube arrays. The separation process is systematically studied in terms of pressure and duration. The findings provide an alternative for efficient separation of ultralow-concentration crude oil-in-water emulsions.

\section{EXPERIMENTAL SECTION}

Titanium foams (thickness: $3 \mathrm{~mm}$, nominal filtration accuracy: $10 \mu \mathrm{m})$ were cleaned in detergent, tap water, alcohol, sulfuric acid and deionized water in ultrasonic bath for $15 \mathrm{~min}$ each. Electrochemical anodization was carried out in ethylene glycol (99.8\% anhydrous, Sigma-Aldrich) with $0.3 \mathrm{wt} \%$ ammonium fluoride and 18.3 vol\% deionized water at $40 \mathrm{~V}$ for $3 \mathrm{~h}$. Prior to the anodization, the foams were soaked in the electrolyte solution for $40 \mathrm{~min}$ to ensure a complete infiltration into the microchannels. The as-anodized samples were rinsed with deionized water and dried by nitrogen stream, and subsequently annealed at $450^{\circ} \mathrm{C}$ for $3 \mathrm{~h}$ in furnace (LE 14/11/B150, Naber-

\footnotetext{
${ }^{1}$ State Key Laboratory of Mechanical Transmission, School of Materials Science and Engineering, Chongqing University, Chongqing 400044, China

2 Jinhai Oil Production Plant, PetroChina Liaohe Oilfield, Panjin 124000, China

* Corresponding author (email: lidong.sun@cqu.edu.cn)
} 
therm). The entire preparation process is schematically illustrated in Fig. S1. The structure of original foams was characterized by X-ray micro-computed tomography ( $\mu \mathrm{CT}$ ) technology (VersaXRM-500). The foam and nanotube morphologies were examined by a field-emission scanning electron microscope (FESEM, FEI Nova 400).

Crude oil (PetroChina Changqing Oilfield) and ultrapure water (Millpore Direct-Q3) were mixed at an oil-to-water volume ratio of $1: 30$, and sonicated for $30 \mathrm{~min}$. This produced the oil-in-water emulsion of a high concentration. The as-prepared high-concentration emulsion was further diluted with water at a volume ratio of 1 to $10,20,30,40$, and 50 , and then sonicated for another $30 \mathrm{~min}$ to prepare ultralow-concentration oil-in-water emulsions. The TOC contents were measured by a TOC analyzer (TOC-L, Shimazu) for detecting the oil concentration. The oil droplets were observed by using a fluorescence optical microscope (Olympus BX53). The attenuated total reflection Flourier transform infrared (ATR-FTIR) spectroscopy was obtained with an FTIR spectrometer (Thermo Scientific Nicolet iS5 FTIR). Finite element simulation was conducted by using a two-phase level set method by the commercial software COMSOL Multiphysics 5.3. The finite element mesh was created with some triangular elements. The target maximum element size was $1.6600 \mu \mathrm{m}$ and the minimum was $0.0192 \mu \mathrm{m}$. The maximum element growth rate was set to 1.08 and the curvature factor was 0.25 in the mesh section. The hydrostatic pressure was set as an independent variable parameter in the simulation.

\section{RESULTS AND DISCUSSION}

Fig. 1a illustrates the 3D inter-connected channels formed in an original porous titanium foam, which are verified by $3 \mathrm{D} \mu \mathrm{CT}$. The reconstructed $\mu \mathrm{CT}$ images reveal an average channel size of about $14 \mu \mathrm{m}$ for the original foam, as shown in Fig. 1b, consistent with the nominal filtration accuracy of $10 \mu \mathrm{m}$. The microchannels provide the infiltration pathway for liquid medium. However, the original foam exhibits a hydrophobic nature with a water contact angle of about $113^{\circ}$ (see Fig. S2), and imparts a very slow infiltration of $62 \mathrm{~min}$ for a water droplet of $5 \mu \mathrm{L}$ (see Fig. S3). In contrast, upon decorating with $\mathrm{TiO}_{2}$ nanotube arrays of open-ended (Fig. 1c, d) and highly-ordered (Fig. 1e) feature, the foam converts into dark color (Fig. S4) and superhydrophilicity with a water contact angle of almost $0^{\circ}$. The water droplet immediately infiltrates into the microchannels in just $49 \mathrm{~ms}$ under the capillary force induced by the nanotubes, as displayed in Fig. If and Video S1. The nanotubes are perpendicular to the channel surface regardless of the position, with the outer diameter being gradually decreased from the bottom to the top because of the curved surface and chemical etching [20-26]. The ridges on the tube walls are resulted from the localized $\mathrm{pH}$ oscillations during nanotube growth $[27,28]$. The superhydrophilic foam demonstrates an underwater oil contact angle of $164^{\circ}$ (Fig. 1g), rendering the underwater superoleophobicity. a

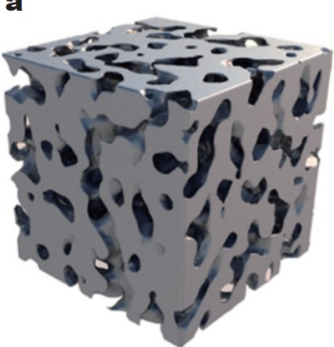

b

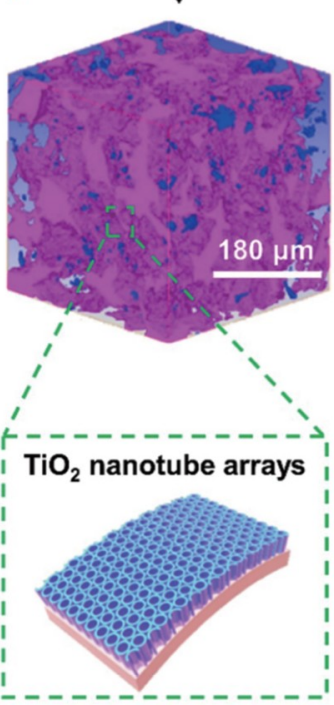

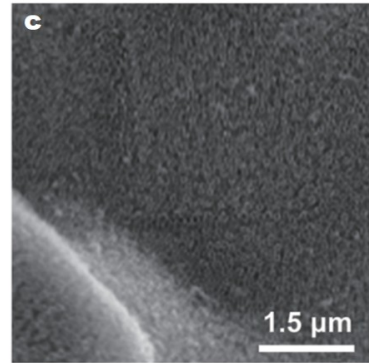
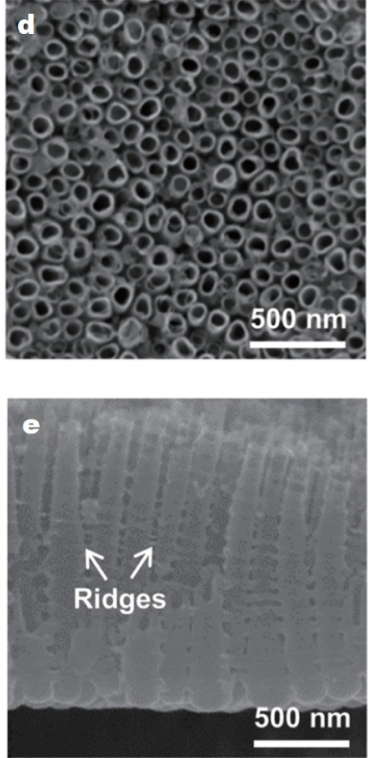

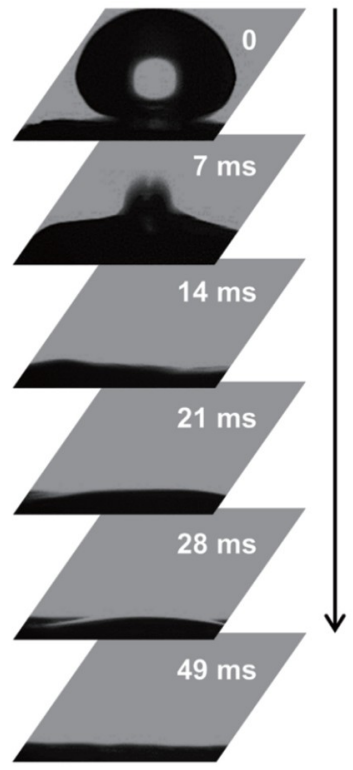

g

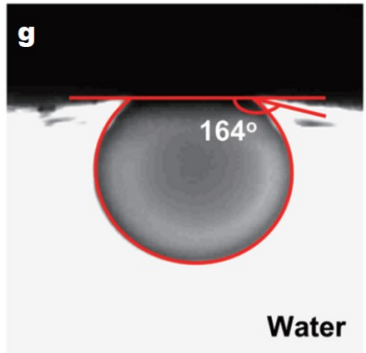

Figure 1 Superhydrophilic microchannels. A schematic illustration (a) and the corresponding reconstructed 3D $\mu \mathrm{CT}$ image (b) of an original titanium foam, where the microchannels are coated with $\mathrm{TiO}_{2}$ nanotube arrays. Typical surface (c, d) and cross-sectional (e) FESEM images of the nanotubes at the microchannels. Water droplet evolution (f) and underwater oil contact angle ( $g$ ) on a nanotube-coated titanium foam. 
Note that the $n$-hexane droplet of about $5 \mu \mathrm{L}$, a major component of crude oil, was used for the underwater wettability test (see Fig. S5 for more measurements using other alkanes). Such a superhydrophilic and underwater superoleophobic feature enables the microchannels as an efficient and competent separator for oil-in-water emulsions.

In general, the crude oil is mainly composed of different alkanes. It can form stable emulsions with water at low concentrations, especially for liquid species with carbon numbers of 6-16. As such, oil/water separation is an essential step in petrochemical industry, and usually becomes much difficult as the oil concentration decreases below $200 \mathrm{ppm}$. Fig. 2a shows a typical photograph of crude oil-in-water emulsion prepared by dispersing the original crude oil (see Fig. S6) in ultrapure water with a dilution ratio of 900 (i.e., $V_{\mathrm{w}} / V_{\mathrm{o}}=900: 1$ ). The oil droplets of $<10 \mu \mathrm{m}$ are clearly visible in the fluorescence optical microscopic photographs, as displayed in Fig. 2b-d (see Fig. S7 for more details). Both the droplet size and concentration decrease with the increased dilution ratio. This is in line with the gradually declined content of total organic carbon in the emulsions, as shown in Fig. 2e. The TOC value drops drastically from an initial $482 \mathrm{ppm}$ at $V_{\mathrm{w}} / V_{\mathrm{o}}$ (the $V_{\mathrm{w}} / V_{\mathrm{o}}$ refers to the water/oil dilution ratio) $=300$ to $<200 \mathrm{ppm}$ at $V_{\mathrm{w}} / V_{\mathrm{o}}=900$, and decreases slightly thereafter. In principle, the small droplets tend to form floated oil layer at the consumption of high surface energy via coalescence $[29,30]$. Nevertheless, the results here indicate that the emulsion keeps relatively stable with a TOC content of $<200 \mathrm{ppm}$, because of the large mean free path at an ultralow concentration.

Fig. $2 \mathrm{f}$ compares the FTIR spectra of the ultrapure water, the original crude oil, and the emulsion. The peaks at 1377 and $1464 \mathrm{~cm}^{-1}$ are assigned to the $\mathrm{C}-\mathrm{H}$ bending in $-\mathrm{CH}_{2}-$ and $-\mathrm{CH}_{3}$ [31-33], respectively. The band at $2850-3000 \mathrm{~cm}^{-1}$ is attributed to $\mathrm{C}-\mathrm{H}$ stretching [30]. This is consistent with the major absorption characteristics of $n$-octane, one of the main components in crude oil, as displayed in Fig. S8. The peak at $1646 \mathrm{~cm}^{-1}$ and the band of $3000-3700 \mathrm{~cm}^{-1}$ are associated with the $-\mathrm{OH}$ bending and $\mathrm{H}-\mathrm{OH}$ stretching models of water molecules [3437], respectively. The spectra keep almost the same for the emulsions of different dilution ratios (see Fig. S9). Accordingly, the FTIR spectrum of the emulsion combines the features of both crude oil and water, further indicating the well-dispersed oil droplets in water.

The crude oil-in-water emulsions were separated by using the superhydrophilic microchannels, as shown in Fig. 3a. The separation apparatus consists of two quartz tubes and one superhydrophilic foam in a sandwiched configuration. The upper tube is filled with emulsion and the lower compartment is used to collect the filtrate that passes through the microchannels. The separation is driven by the hydrostatic pressure which is in turn controlled by the constant feed height during the entire process.

The separation performance was examined in terms of TOC content and separation efficiency under different pressures. The ultralow-concentration emulsions with a dilution ratio of $V_{\mathrm{w}} / V_{\mathrm{o}}$ $=900$ (original TOC content $<200 \mathrm{ppm}$ ) are employed in the separation. Fig. $3 \mathrm{~b}$ reveals that the TOC content in the filtrate decreases with the enhanced pressure and exhibits a minimum value of about $6 \mathrm{ppm}$ at $12.25 \mathrm{kPa}$, and drastically increases thereafter. In the meanwhile, the separation efficiency renders an opposite varying trend with a maximum point of $96.8 \%$ at $12.25 \mathrm{kPa}$. The plots can thus be divided into three regions with reference to the pressure, i.e., Regions I, II, and III.

The oil droplets follow an approximate Brownian motion in emulsion [37], because of water molecule collision. As such, the droplets are capable of growing up by collision and coalescence, and eventually form an oil layer on the emulsion surface, as illustrated in Fig. S10. It is a spontaneous and slow demulsification process in an emulsion. However, the demulsification accelerates in the presence of superhydrophilic microchannels and hydrostatic pressure. The microchannels allow the water to pass through freely while expel the oil droplets back to the bulk
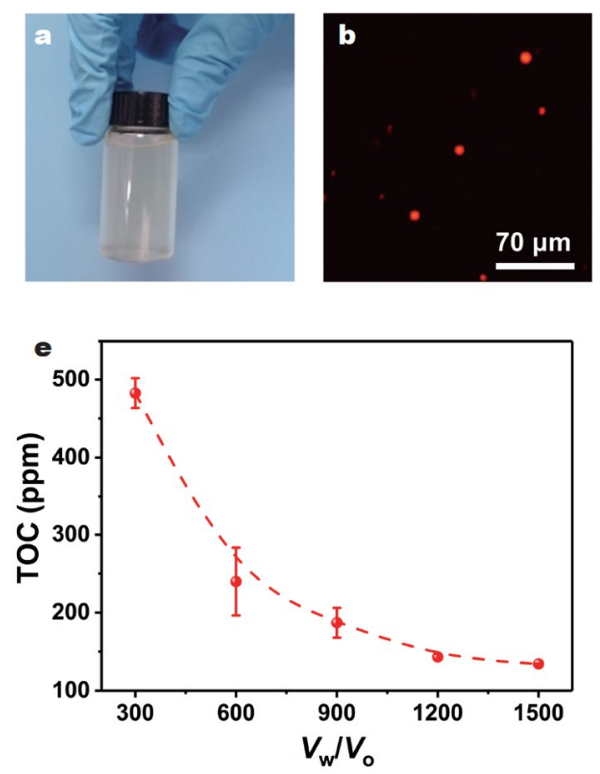
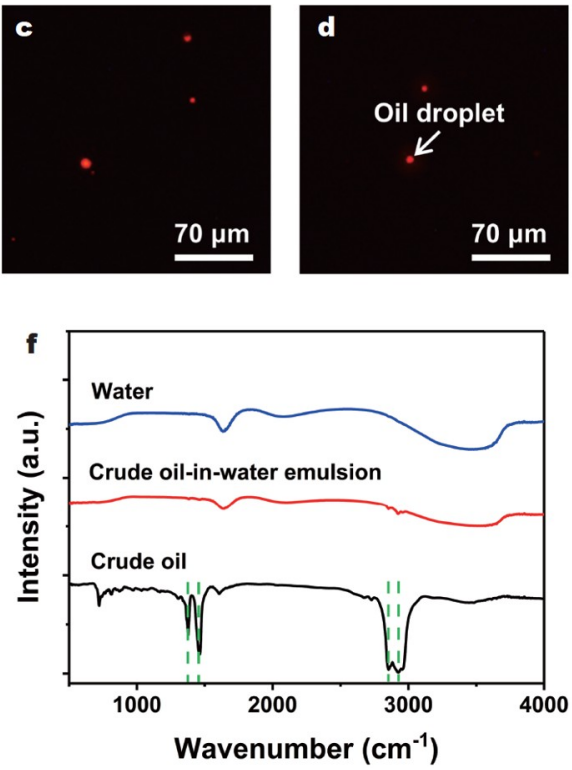

Figure 2 Crude oil-in-water emulsion. A typical photograph (a) and fluorescence optical microscopic photographs (b-d) of crude oil-in-water emulsions with a dilution ratio $\left(V_{\mathrm{w}} / V_{\mathrm{o}}\right)$ of $300(\mathrm{~b}), 900(\mathrm{a}, \mathrm{c})$, and $1500(\mathrm{~d})$. (e) The TOC content as a function of dilution ratio. (f) FTIR spectra of water, crude oil, and crude oil-in-water emulsion $\left(V_{\mathrm{w}} / V_{\mathrm{o}}=900\right)$. 
a
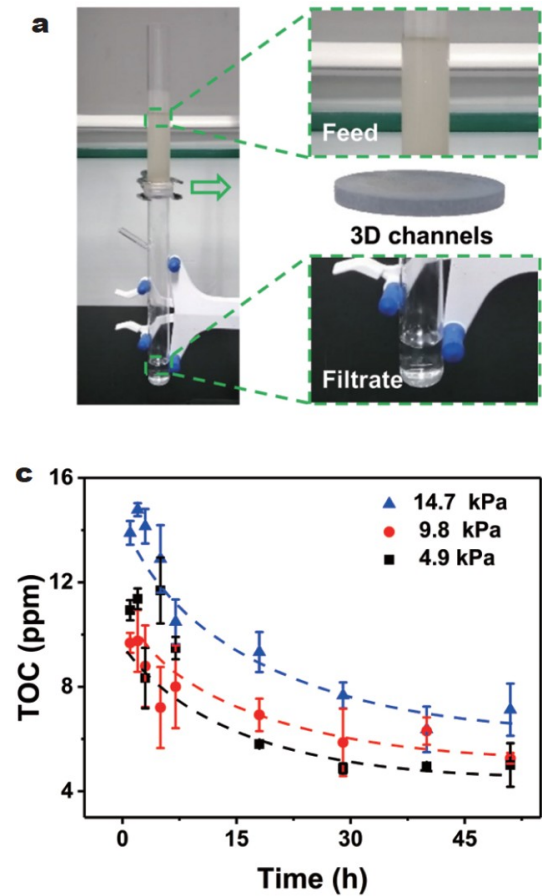
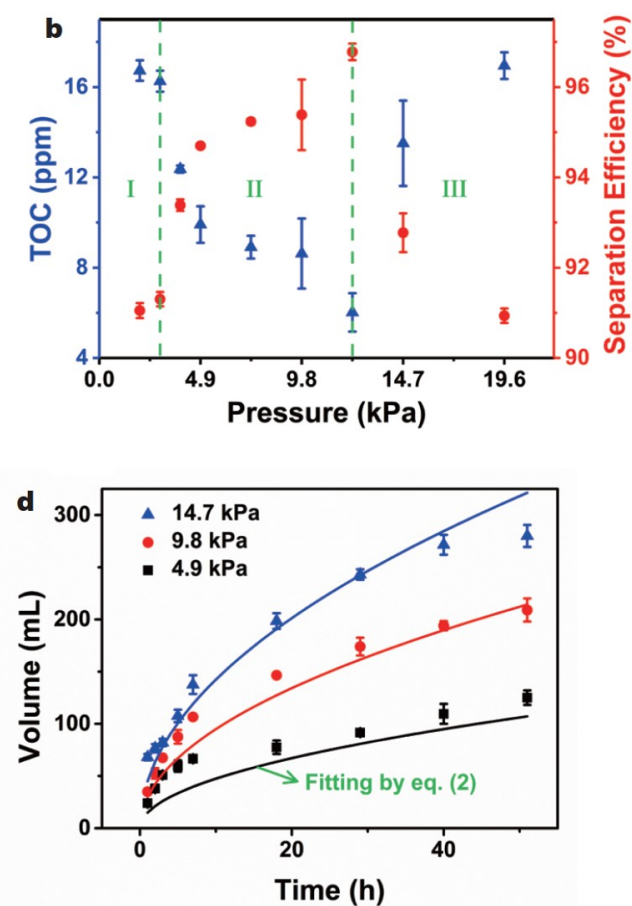

Figure 3 Emulsion separation. (a) Experimental setup. (b) TOC content and separation efficiency as a function of pressure. The changes of TOC content (c) and filtrate volume (d) with time under different separation pressures.

emulsion, in light of the superhydrophilic and underwater superoleophobic feature (see Fig. 1). This concentrates the emulsion and therefore promotes the collision and coalescence, facilitating the demulsification. In the meantime, the hydrostatic pressure imposed by the emulsion height affects the mean free path of the oil droplets, especially for those close to the foam surface. The mean free path decreases with the enlarged pressure, which is beneficial to the coalescence of droplets. Under low pressures in Region I, the TOC content and separation efficiency change slightly, as exhibited in Fig. 3b. In Region II, the demulsification performance enhances with the pressure because of the decreased mean free path. Nonetheless, the separation degrades in Region III, as the oil droplets are also driven through the microchannels under too high a pressure.

The influence of the hydrostatic pressure is well supported by the finite element simulation. Fig. 4a compares the emulsion separation process under different pressures. In the first $3 \times$ $10^{-4} \mathrm{~s}$, no obvious differences are present between different systems (see Fig. S11 for details). The oil droplets gradually coalesce with a larger rate under a higher pressure, thus leading to the increment in droplet size with pressure. At $0.001 \mathrm{~s}$, the droplets that are close to the channel inlets infiltrate into the microchannels. The infiltration depth increases with the pressure, and the droplets are even driven out of the channels at $19.60 \mathrm{kPa}$. Subsequently, at a critical pressure of $12.25 \mathrm{kPa}$, the merged droplets that are larger than the channel size adsorb to the foam surface, progressively grow up, and eventually float up at a critical size. In contrast, at a higher pressure of $19.60 \mathrm{kPa}$, the droplets are continuously forced into the channels before reaching the critical size, therefore deteriorating the separation performance. At lower pressures, the coalescing and growing processes are slowed down. Based on the simulations, the maximum droplet size that can be achieved in the separation process is summarized in Fig. 4b. The plot can also be divided into three similar regions. This well echoes the experimental results in Fig. 3b, and further discloses the essential role of pressure in emulsion separation.

The separation stability of the microchannels was further investigated by continuously feeding the upper compartment with ultralow-concentration emulsion up to $51 \mathrm{~h}$. The TOC content in the collected filtrates declines with time regardless of the pressure, as presented in Fig. $3 \mathrm{c}$. This is attributed to the gradually concentrated emulsions that facilitate the demulsification process. In the first a few hours, the pressure dependence of the TOC content agrees well with the varying trend in Fig. 3b. However, a lower pressure generally gives rise to a better separation behavior after $7 \mathrm{~h}$. This is due to the accumulated oil film in the feeding compartment that affects the emulsion concentration and hence shifts the critical pressure.

Fig. $3 \mathrm{~d}$ shows the changes of filtrate volume with time under different pressures. The volume increases as the separation prolongs, whereas the filtration rate gradually decreases. This is attributed to (1) the promoted emulsion viscosity with the increased oil content, and (2) the adsorbed oil droplets on the microchannel surface. The FTIR spectrum of the superhydrophilic foam upon using for $51 \mathrm{~h}$ (see Fig. S12) discloses the presence of $\mathrm{C}-\mathrm{H}$ stretching vibration mode, demonstrating the remained crude oil on the surface that could narrow and block the microchannels. This results in the gradually declined filtration rate as the separation proceeds.

Besides, the amount of collected filtrate enhances with the hydrostatic pressure. The filtrate volume can be expressed based on the Darcy's law [38-40], as follows:

$V=k \Delta P t^{\frac{1}{2}}$,

where $k$ is an empirical proportion coefficient, $\Delta P$ is the trans- 
foam pressure drop, and $t$ is the filtration time. The value of $k$ is determined to be about 15 by fitting the data at $4.9 \mathrm{kPa}$ in Fig. 3d. As such, Equation (1) can be expressed as

$V=15 \Delta P t^{\frac{1}{2}}$.

The fitting curves are in good agreement with the experimental results at 9.8 and $14.7 \mathrm{kPa}$. This further suggests the essential roles of the promoted viscosity and the adsorbed droplets in the separation process, as the filtration flux is directly associated with the feed viscosity and crude oil blockage resistance according to the Darcy's law. The well-fitted curves confirm that the separation process of crude oil-in-water emulsions follows the conventional cake filtration theory [41]. The separation rate decreases as the oil droplets gradually adsorb on the channel surface.

The durability of the superhydrophilic foams was further evaluated with recycling and harsh-environment tests. Fig. 5a shows that the TOC content and separation efficiency keep almost unchanged after 10 cycles of emulsion separation with the superhydrophilic foams at $12.25 \mathrm{kPa}$, maintaining around $6 \mathrm{ppm}$ and $96.5 \%$, respectively. Although there are slight contaminants on the recycled foam surface in direct contact with the emulsion (see Fig. S13), the nanotubes are still clearly visible after 10 cycles, suggesting the high mechanical stability of the nanotubes on the microchannel surface. Fig. $5 \mathrm{~b}$ displays that the foams also exhibit good separation performance after long-term soaking in harsh environments (acid, base or high salinity environment), with a high separation efficiency of $>96.0 \%$ and low TOC content of $<7.5 \mathrm{ppm}$. This implies the high chemical stability of the nanotubes. Besides, the superhydrophilic foams perform better under base condition.

The separation efficiency $(\eta)$ of oil-in-water emulsion is defined as $[41,42]$

$\eta=\left(\frac{c_{\mathrm{e}}-c_{\mathrm{f}}}{c_{\mathrm{e}}}\right) \times 100 \%$,

where $C_{\mathrm{e}}$ and $C_{\mathrm{f}}$ are the TOC contents in the original emulsion and filtrate, respectively. Equation (3) indicates that the separation efficiency is closely related to the oil concentration in the original emulsion, and a high efficiency is easily obtainable with high-concentration emulsions.

Fig. 6a reveals that the theoretical efficiency drops drastically with the original TOC content of $<1000 \mathrm{ppm}$. In the case of ultralow-concentration emulsion of $<200 \mathrm{ppm}$, the separation efficiency is theoretically smaller than $97.5 \%$ for a given TOC content of $5 \mathrm{ppm}$ in the filtrates. In this study, a high efficiency of $96.8 \%$ and low TOC content of $6 \mathrm{ppm}$ is achieved, which is close to the theoretical limit imposed by the ultralow concentration. This demonstrates the advances of superhydrophilic microchannels over the existing methods. To date, there are few reports on the separation of ultralow-concentration emulsion system, not to mention the crude oil in a complicated mixture form. Fig. $6 \mathrm{~b}$ summarizes the relevant studies on ultralow-concentration emulsions in terms of water/oil dilution ratio, separation efficiency and pressure. It clearly discloses the superior performance of the titanium microchannels, as compared with the conventional organic membranes and inorganic frameworks.
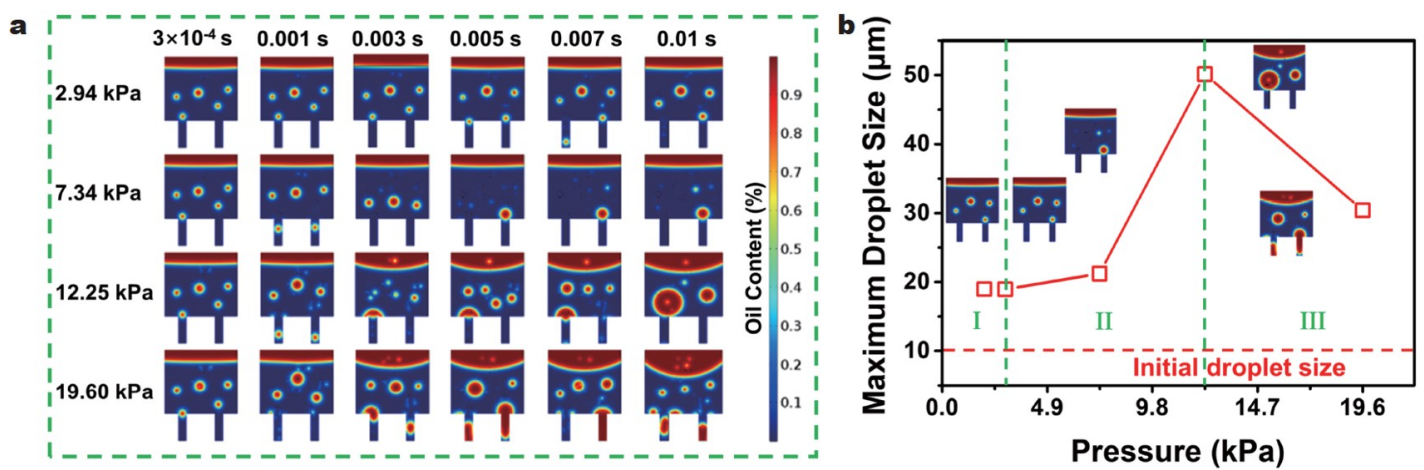

Figure 4 Finite element simulation of emulsion separation. (a) Emulsion separation process under different pressures (initial oil droplet size: $10 \mu \mathrm{m}$; microchannel size: $14 \mu \mathrm{m}$ ). (b) Maximum oil droplet size as a function of pressure. The critical dimension is $130 \mu \mathrm{m} \times 160 \mu \mathrm{m}$ for the simulation models herein.
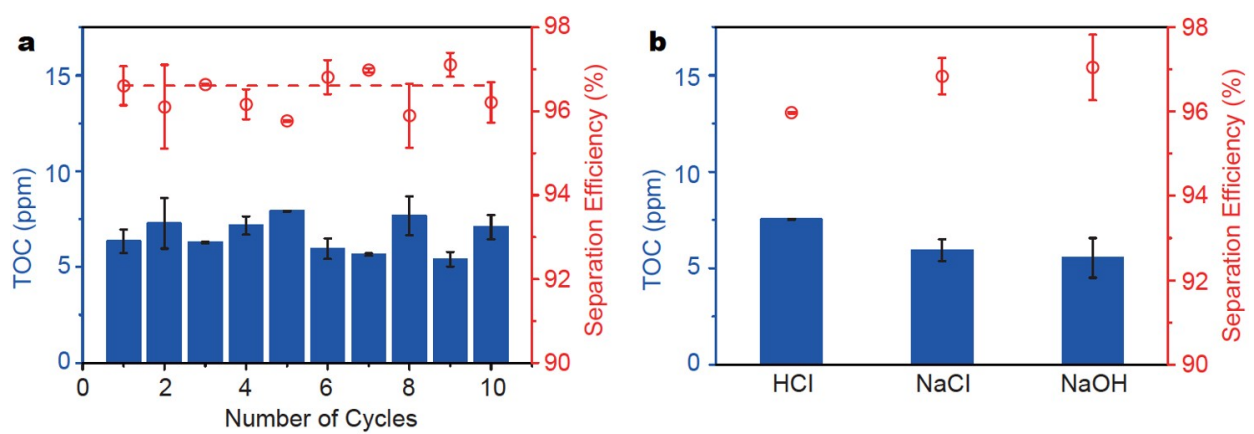

Figure 5 Durability tests. (a) Recycling tests and (b) separation performance in harsh environments (soaking the foams in $2 \mathrm{~mol} \mathrm{~L}^{-1} \mathrm{HCl}, \mathrm{NaCl}$ or $\mathrm{NaOH}$ solution for $3 \mathrm{~h}$ prior to the separation) for separating the crude oil-in-water emulsion $\left(V_{\mathrm{w}} / V_{\mathrm{o}}=900\right)$ with superhydrophilic foams at $12.25 \mathrm{kPa}$. 

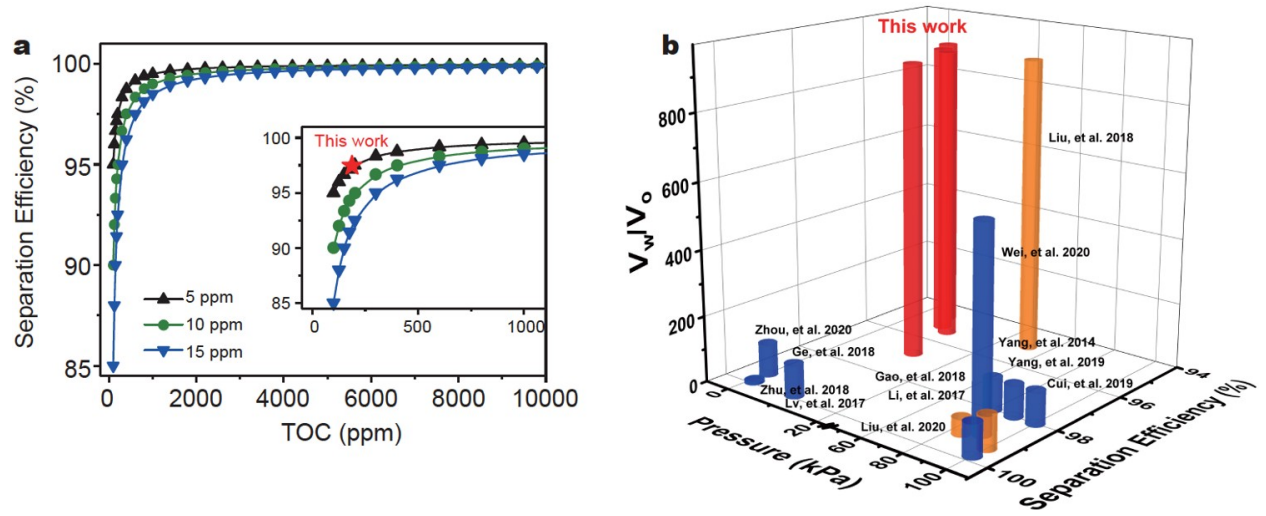

Figure 6 Performance comparison. (a) Theoretical calculation of separation efficiency using Equation (3) and TOC content of 5, 10 and 15 ppm in the filtrates. (b) Comparison with the state-of-the-art reports. The organic membranes and inorganic frameworks are indicated with blue and orange colors, respectively.

\section{CONCLUSIONS}

In conclusion, the 3D microchannels of superhydrophilic and underwater superoleophobic feature are developed by percolative anodization. A high separation efficiency of $96.8 \%$ and low TOC content of $6 \mathrm{ppm}$ are achieved using the microchannels, toward separating the crude oil-in-water emulsion of ultralow concentration $(<200 \mathrm{ppm})$. A critical separation pressure of $12.25 \mathrm{kPa}$ is obtained for titanium foams of $3 \mathrm{~mm}$ in thickness and $14 \mu \mathrm{m}$ in average channel size. The findings are promising for future applications in petrochemical industry, water treatment, and other relevant fields.

\section{Received 12 April 2021; accepted 4 June 2021;} published online 12 August 2021

1 Gao S, Sun J, Liu P, et al. A robust polyionized hydrogel with an unprecedented underwater anti-crude-oil-adhesion property. Adv Mater, 2016, 28: 5307-5314

2 Zhu Y, Xie W, Zhang F, et al. Superhydrophilic in-situ-cross-linked zwitterionic polyelectrolyte/PVDF-blend membrane for highly efficient oil/water emulsion separation. ACS Appl Mater Interfaces, 2017, 9: 9603-9613

3 Zhang S, Jiang G, Gao S, et al. Cupric phosphate nanosheets-wrapped inorganic membranes with superhydrophilic and outstanding anticrude oil-fouling property for oil/water separation. ACS Nano, 2018, 12: 795803

4 Zhang Y, Guo J, Han G, et al. Molecularly soldered covalent organic frameworks for ultrafast precision sieving. Sci Adv, 2021, 7: eabe8706

5 Zhao Y, Yang X, Yan L, et al. Biomimetic nanoparticle-engineered superwettable membranes for efficient oil/water separation. J Membrane Sci, 2021, 618: 118525

6 Bragg JR, Prince RC, Harner EJ, et al. Effectiveness of bioremediation for the Exxon Valdez oil spill. Nature, 1994, 368: 413-418

7 Harvey S, Elashvili I, Valdes JJ, et al. Enhanced removal of Exxon Valdez spilled oil from Alaskan gravel by a microbial surfactant. Nat Biotechnol, 1990, 8: 228-230

8 Ge J, Shi LA, Wang YC, et al. Joule-heated graphene-wrapped sponge enables fast clean-up of viscous crude-oil spill. Nat Nanotech, 2017, 12: $434-440$

9 da Silva Jr. UG, de F. Melo MA, da Silva AF, et al. Adsorption of crude oil on anhydrous and hydrophobized vermiculite. J Colloid Interface Sci, 2003, 260: 302-304

10 Wu MB, Huang S, Liu TY, et al. Compressible carbon sponges from delignified wood for fast cleanup and enhanced recovery of crude oil spills by Joule heat and photothermal effect. Adv Funct Mater, 2021, 31: 2006806
11 Hammoud AH, Khalil MF. Performance of a rotating drum skimmer in oil spill recovery. Proc Institution Mech Engineers Part E-J Process Mech Eng, 2003, 217: 49-57

12 Broje V, Keller AA. Improved mechanical oil spill recovery using an optimized geometry for the skimmer surface. Environ Sci Technol, 2006, 40: 7914-7918

13 Boylan DB, Tripp BW. Determination of hydrocarbons in seawater extracts of crude oil and crude oil fractions. Nature, 1971, 230: 44-47

14 Zhu Y, Wang J, Zhang F, et al. Zwitterionic nanohydrogel grafted PVDF membranes with comprehensive antifouling property and superior cycle stability for oil-in-water emulsion separation. Adv Funct Mater, 2018, 28: 1804121

15 Zhang W, Zhu Y, Liu X, et al. Salt-induced fabrication of superhydrophilic and underwater superoleophobic PAA-g-PVDF membranes for effective separation of oil-in-water emulsions. Angew Chem Int Ed, 2014, 53: 856-860

16 Nikolov AD, Randie M, Shetty CS, et al. Chemical demulsification of oil-in-water emulsion using air-flotation: The importance of film thickness stability. Chem Eng Commun, 1996, 152-153: 337-350

17 Shi G, Shen Y, Mu P, et al. Effective separation of surfactant-stabilized crude oil-in-water emulsions by using waste brick powder-coated membranes under corrosive conditions. Green Chem, 2020, 22: 13451352

$18 \mathrm{Xu} \mathrm{H}$, Jia W, Ren S, et al. Magnetically responsive multi-wall carbon nanotubes as recyclable demulsifier for oil removal from crude oil-inwater emulsion with different pH levels. Carbon, 2019, 145: 229-239

19 Zhang J, Zhang F, Wang A, et al. Zwitterionic nanofibrous membranes with a superior antifouling property for gravity-driven crude oil-inwater emulsion separation. Langmuir, 2019, 35: 1682-1689

20 Sun L, Zhang S, Wang Q. Conformal growth of anodic nanotubes for dye-sensitized solar cells: Part II. Nonplanar electrode. J Nanosci Nanotech, 2014, 14: 2050-2064

21 Sun L, Wang X, Li M, et al. Anodic titania nanotubes grown on titanium tubular electrodes. Langmuir, 2014, 30: 2835-2841

22 Xiang C, Sun L, Wang Y, et al. Large-scale, uniform, and superhydrophobic titania nanotubes at the inner surface of $1000 \mathrm{~mm}$ long titanium tubes. J Phys Chem C, 2017, 121: 15448-15455

23 Wang Y, Sun L, Xiang C, et al. Coaxial anodic oxidation under dynamic electrolyte conditions for inner surface patterning of high-aspect-ratio and slim Ti tubes. Corrosion Sci, 2017, 124: 193-197

24 Sun L, Zhang S, Sun XW, et al. Effect of electric field strength on the length of anodized titania nanotube arrays. J Electroanal Chem, 2009, 637: 6-12

25 Sun L, Zhang S, Wang X, et al. A novel parallel configuration of dyesensitized solar cells with double-sided anodic nanotube arrays. Energy Environ Sci, 2011, 4: 2240-2248

26 Sun L, Zhang S, Sun XW, et al. Double-sided anodic titania nanotube 
arrays: A lopsided growth process. Langmuir, 2010, 26: 18424-18429 Sun L, Zhang S, Wang X, et al. Transition from anodic titania nanotubes to nanowires: Arising from nanotube growth to application in dye-sensitized solar cells. ChemPhysChem, 2011, 12: 3634-3641

28 Tsui L, Homma T, Zangari G. Photocurrent conversion in anodized $\mathrm{TiO}_{2}$ nanotube arrays: Effect of the water content in anodizing solutions. J Phys Chem C, 2013, 117: 6979-6989

29 Denkov ND, Petsev DN, Danov KD. Interaction between deformable brownian droplets. Phys Rev Lett, 1993, 71: 3226-3229

30 Gorce JP, Spells SJ. FTIR studies of conformational disorder: Crystal perfecting in long chain $n$-alkanes. Polymer, 2004, 45: 3297-3303

31 Snavely DL, Dubsky J. Near-IR spectra of polyethylene, polyethylene glycol, and polyvinylethyl ether. J Polym Sci A Polym Chem, 1996, 34: 2575-2579

32 Asemani M, Rabbani AR. Oil-oil correlation by FTIR spectroscopy of asphaltene samples. Geosci J, 2016, 20: 273-283

33 Zzeyani S, Mikou M, Naja J, et al. Spectroscopic analysis of synthetic lubricating oil. Tribol Int, 2017, 114: 27-32

34 Al-Hosney HA, Grassian VH. Water, sulfur dioxide and nitric acid adsorption on calcium carbonate: A transmission and ATR-FTIR study. Phys Chem Chem Phys, 2005, 7: 1266-1276

35 Schofield DP, Kjaergaard HG. Calculated OH-stretching and $\mathrm{HOH}-$ bending vibrational transitions in the water dimer. Phys Chem Chem Phys, 2003, 5: 3100-3105

36 Zhang $\mathrm{Y}$, Cheng $\mathrm{X}$, Jiang $\mathrm{X}$, et al. Robust natural nanocomposites realizing unprecedented ultrafast precise molecular separations. Mater Today, 2020, 36: 40-47

37 Batchelor GK. The effect of Brownian motion on the bulk stress in a suspension of spherical particles. J Fluid Mech, 1977, 83: 97-117

38 Lee Y, Clark MM. Modeling of flux decline during crossflow ultrafiltration of colloidal suspensions. J Membrane Sci, 1998, 149: 181-202

39 McDowell NG, Allen CD. Darcy's law predicts widespread forest mortality under climate warming. Nat Clim Change, 2015, 5: 669-672

40 Gutiérrez JP, van Halem D, Uijttewaal WSJ, et al. Natural recovery of infiltration capacity in simulated bank filtration of highly turbid waters. Water Res, 2018, 147: 299-310

41 Zang L, Ma J, Lv D, et al. A core-shell fiber-constructed $\mathrm{pH}$-responsive nanofibrous hydrogel membrane for efficient oil/water separation. J Mater Chem A, 2017, 5: 19398-19405

42 Jin J, Zhao X, Du YH, et al. Nanostructured three-dimensional percolative channels for separation of oil-in-water emulsions. iScience, 2018, 6: 289-298

Acknowledgements This work was supported by the National Natural Science Foundation of China (51871037), Chongqing Youth Talents Program (CQYC201905023), and the National Key Research and Development Program of China (2020YFF0421893).

Author contributions Sun L conceived the idea, supervised the project, and revised the manuscript. Jin J carried out the experiments and drafted the manuscript. Su J, Xiang C, Li H, and Zhao K assisted in device preparation and testing. Xu B provided valuable discussion and suggestion on the project. All of the authors analyzed the experimental results and contributed to the final manuscript.

Conflict of interest The authors declare that they have no conflict of interest.

Supplementary information Supporting data are available in the online version of the paper.

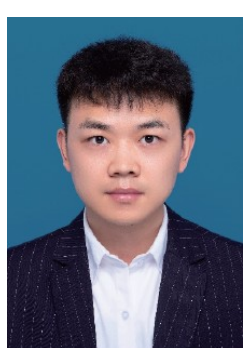

Jian Jin received his BE degree in metallurgical engineering from Jiangsu University in 2015 . He is currently a $\mathrm{PhD}$ student under the supervision of Prof. Lidong Sun at the School of Materials Science and Engineering, Chongqing University. His research interest includes superwetting microchannels and oil/ water separation.

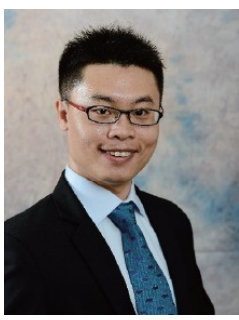

Lidong Sun received his $\mathrm{PhD}$ degree from Nanyang Technological University, Singapore, in 2012. He worked as a postdoctoral research fellow at the National University of Singapore from 2011 to 2014, and thereafter joined Chongqing University. $\mathrm{He}$ is currently a professor at the School of Materials Science and Engineering, Chongqing University. His research interest includes electrochemistry and materials science at the nanoscale, with a particular focus on functional coatings for tubes/microchannels.

\section{基于三维超浸润微通道的超低浓度原油乳液高效去 乳研究}

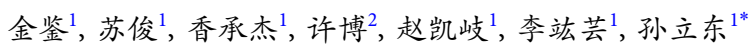

摘要 原油作为全球关注热点和需求巨大的主要能源, 其高效提取在 能源与环境领域至关重要. 然而, 针对超低含油量 $(<200 \mathrm{ppm})$ 原油乳液 的分离, 仍然存在巨大挑战. 本文利用多孔钛表面原位生长的 $\mathrm{TiO}_{2}$ 纳米 管阵列涂层, 制备了三维超浸润微通道. 该通道展现了超亲水且水下超 疏油的特征, 能够快速形成水膜通道而排斥油滴. 据此, 实现了对超低 浓度水包原油乳液的高效分离，分离效率高达 $96.8 \%$, 滤液中的总有机 碳含量仅约 $6 \mathrm{ppm}$. 本文系统研究了分离过程中的压力与时间影响因 素, 结果显示最佳临界分离压力为 $12.25 \mathrm{kPa}$. 该分离性能接近于超低浓 度原油乳液的分离理论极限. 与有机膜或无机框架分离材料相比, 该三 维超浸润微通道呈现出显著优势. 